\title{
Tumor de Células Granulares no Canal Anal: Relato de Caso e Revisão de Literatura
}

\section{Granular Cell Tumor in the Anal Canal: Case Report and Literature Review}

\author{
BIANCA ANDREUCCI LIMA MOREIRA SANTONI ${ }^{1}$;ABIO EDUARDO SOUZA PINTO ${ }^{1}$; \\ LEONARDO MACHADO'; EDNA DELABIO FERRAZ ${ }^{1,3}$; GISELA GUTIERREZ DEL CUETO'; \\ CRISTINE MARIA QUINTAS ${ }^{2}$; RONALDO COELHO SALLES ${ }^{1,4}$
}

\author{
1. Médico do Hospital Municipal Miguel Couto, Rio de Janeiro, Brasil; ${ }^{2}$ Médico do Hospital Universitário/UFRJ, \\ Rio de Janeiro, Brasil; ${ }^{3}$ Médico do Hospital da Lagoa, Rio de Janeiro, Brasil; ${ }^{4}$ Chefe do Serviço de Coloproctologia, \\ HMMC, Rio de Janeiro, Brasil
}

SANTONI BALM; PINTO FES; MACHADO L; FERRAZ ED; CUETO GGD; SALLES RC. Tumor de Células Granulares no Canal Anal: Relato de Caso e Revisão de Literatura. Rev bras Coloproct, 2006;26(4): 454-458.

RESUMO: Os autores relatam o caso de uma paciente de 28 anos em que foram diagnosticados múltiplos tumores de células granulares em canal anal, não relacionados com a queixa inicial. $O$ tumor de células granulares é incomum, se apresentando geralmente como um tumor benigno que pode se localizar em qualquer segmento corpóreo. A apresentação no trato gastrointestinal é rara. Na literatura mundial são relatados apenas dois casos em canal anal. São discutidos os aspectos clínicos e diagnósticos do tumor de células granulares no trato gastrointestinal, principalmente no reto e ânus, assim como a terapêutica recomendada. É apresentada também uma revisão com base na literatura mundial, enfatizando a ocorrência do Tumor de Células Granulares em canal anal.

Descritores: Tumor de células granulares; Mioblastoma de células granulares; Trato gastrointestinal; Reto; Canal anal.

\section{INTRODUÇÃO}

O tumor de células granulares (TCG) do cólon é uma lesão mesenquimal incomum. É um tumor relativamente raro que pode estar localizado em qualquer parte do corpo. Comumente surge na cavidade oral e tecido subcutâneo sendo, porém, incomum no colon, reto e canal anal.

No trato gastrointestinal, o esôfago é o local mais acometido ${ }^{1}$ em ocorrência. Na maioria dos casos, o TCG gastrointestinal é achado acidental durante a endoscopia ${ }^{2}$ O local mais comum é a região anorretal e cólon ascendente. O tumor é benigno, aparece como um nódulo submucoso menor que dois centímetros de diâmetro.

O relato do caso chama a atenção para a rara apresentação em canal anal. Baseamos esta afirmação em uma revisão da literatura mundial sobre o tema, utilizando os sistemas MEDLINE DATABASE,
COCHRANE, LILACS, além de mecanismos de busca da rede global de computadores mais conhecidos.

\section{RELATO DO CASO}

CQS, 28 anos, sexo feminino, negra, solteira, apresentou-se no ambulatório com queixa de dor em ânus iniciada há seis meses, acompanhada de alteração do hábito intestinal (evacuações com intervalos de três dias). Negou eliminação de secreção, muco, pus ou sangue pelas fezes. Referiu que há nove meses teve início de dor em fossa ilíaca esquerda. Não havia história de neoplasia na família. Relatou exame VDRL positivo em 2001, sendo submetida a tratamento clínico.

\section{Exame Proctológico}

A inspeção era normal. Ao toque, apresentava tumoração de consistência firme e lobulada, medindo

Trabalho realizado no Hospital Municipal Miguel Couto - Serviço de Coloproctologia - Rio de Janeiro, Brasil.

$\overline{\text { Recebido em } 14 / 06 / 2006}$

Aceito para publicação em 24/07/2006 
cerca de $2 \mathrm{~cm}$ de diâmetro em parede anterior do canal anal. À anuscopia, notava-se revestimento anal de coloração avermelhada, com elevação nítida. Realizada retossigmoidoscopia que evidenciou outra lesão semelhante, elevada, a cerca de $10 \mathrm{~cm}$ da margem anal, em parede posterior do reto .

\section{Conduta inicial - Biópsia excisional}

Em dezembro de 2004 foi realizada biópsia excisional em nódulo de canal anal, e foram visualizadas outras lesões nodulares, endurecidas, submucosas, de coloração amarelo-brancacenta em toda circunferência do canal anal (em número aproximado de sete). O resultado histopatológico foi de tumor de células granulares.

\section{Colonoscopia}

Em fevereiro de 2005, foi submetida à colonoscopia:

- canal anal - lesões sésseis, de aspecto brancacento, submucosos e de tamanhos variados (cerca de sete lesões);

- retossigmóide - uma lesão de aspecto submucoso medindo $1 \mathrm{~cm}$ de diâmetro, séssil e brancacenta;

- cólon transverso - lesão polipóide, séssil, brancacenta, de $0,5 \mathrm{~cm}$, que foi biopsiada. O laudo histopatológico foi de pólipo hiperplásico.

\section{Ressonância Magnética}

Em maio de 2005, foi realizada ressonância magnética de pelve que visualizou apenas um mioma uterino. Gordura peri-retal e fossa isquiática não apresentavam alterações apreciáveis.

\section{Tratamento cirúrgico}

Em junho de 2005, foi submetida ao último procedimento cirúrgico que consistiu em exérese de lesão em canal anal, indicada pelo aumento indiscutível de seu volume. Foi realizada através de acesso transanal, com incisão transversal logo acima da linha pectínea, exérese desta que se encontrava bem aderida à submucosa. A lesão foi pouco difícil de ser enucleada (Figura 1).

\section{Histopatológico}

Confirmou o laudo anterior de tumor de células granulares, que se caracteriza por células granulares de forma ovóide com núcleo pequeno e abundante citoplasma eosinófílico, contendo inúmeros grânulos. (Figuras 2, 3 e 4).

A imunohistoquímica demonstra uma expressão de vimetina, proteína S-100, enolase neuronal-específica e PGP (produto do gene da proteína).

\section{Evolução e seguimento}

Em sua mais recente consulta ( $4^{\circ}$ mês de pósoperatório) apresentava-se sem queixas. Ao exame, a parede em que foi realizada a excisão tinha aparência de tecido fibrótico. Nenhuma outra alteração foi encontrada no canal anal e reto inferior.

A paciente segue em acompanhamento ambulatorial semestral, com avaliação colonoscópica anual programada.

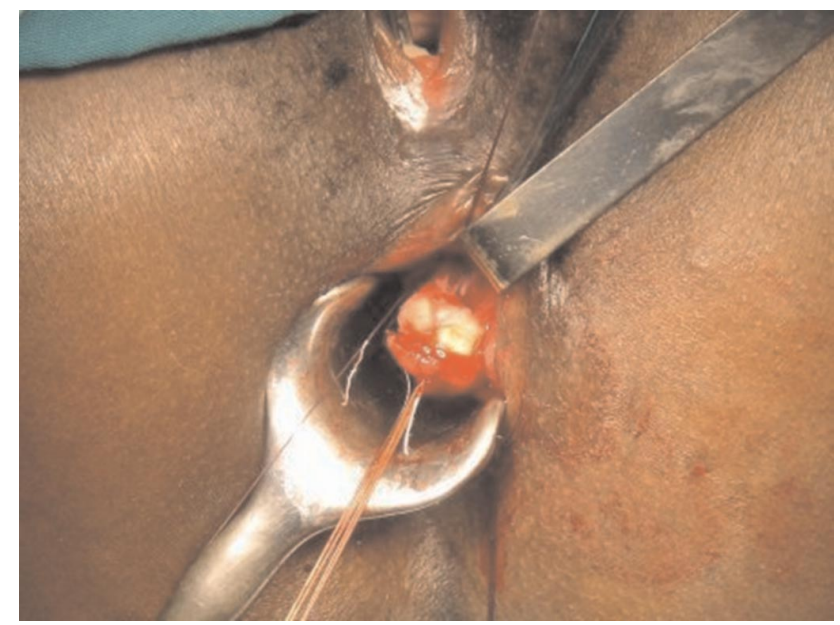

Figura 1 - Aspecto da lesão em canal anal, tratada com excisão cirúrgica. Note a coloração amarelo-brancacenta característica.

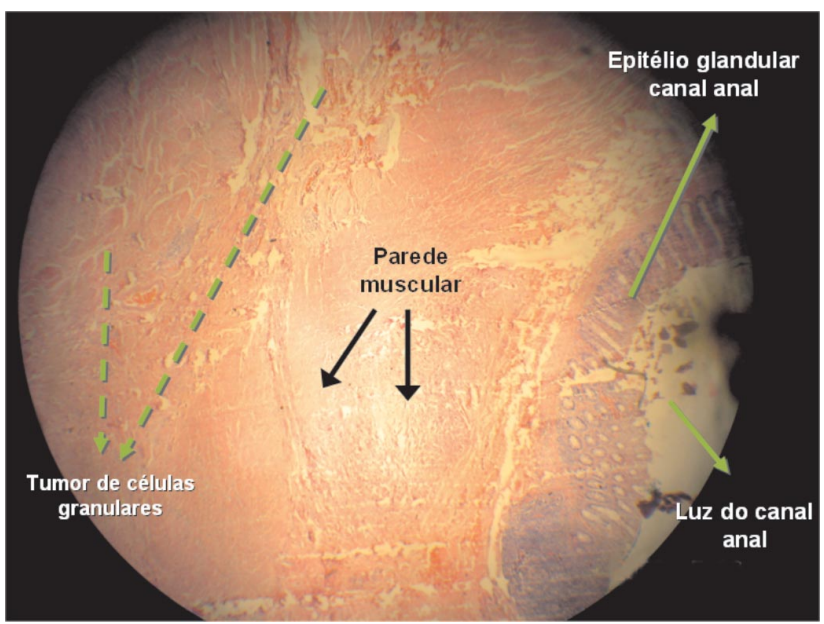

Figura 2 - Corte histológico da peça, evidenciando detalhamento dos planos em relação ao tumor. Nota-se o plano muscular do canal anal, seu epitélio glandular à direita, e o tecido tumoral à esquerda (aumento $10 x$ ). 


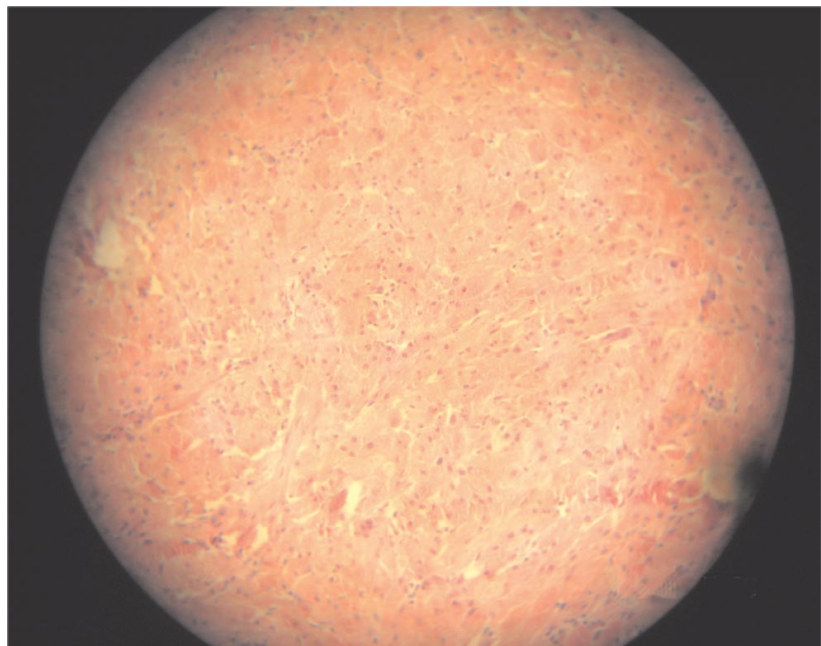

Figura 3 - Característica celularidade do tumor de células granulares (aumento $10 x$ ).

\section{DISCUSSÃO}

O tumor de células granulares foi inicialmente descrito por Abri Kossoff em 1926, que relatou poder surgir virtualmente em qualquer parte do corpo, mas raramente encontrada no trato gastrointestinal ${ }^{3}$.

Parece surgir das células de Schwann. Logo foi observada uma relação íntima do TGI com os nervos periféricos ${ }^{4}$. Mais recentemente, a teoria da célula de Schwann foi constatada pela coloração positiva do citoplasma e núcleo de células granulares para proteína S-100. As colorações adicionais para as células granulares de proteína mielina e glicoproteína mielo-associadas confirmam esta hipótese ${ }^{5}$.

A incidência é maior no sexo feminino do que no masculino $(1,3: 1)$ e a idade média é de 31 a 49 anos $^{3}$.

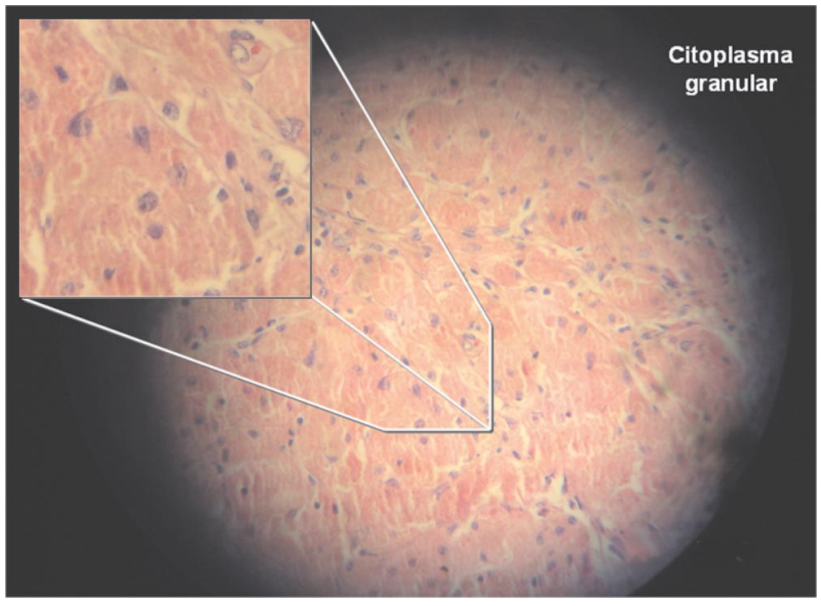

Figura 4 - Detalhe do citoplasma abundantemente granular eosinofílico, confirmando o diagnóstico histopatológico (aumento $40 x)$.

O TCG geralmente se apresenta como um nódulo pequeno, pobremente circunscrito, submucoso, com diâmetro menor que $2 \mathrm{~cm}$, com curso clínico benigno. É múltiplo em apenas $10-20 \%$ dos casos. ${ }^{1}$ Apresenta recidiva em torno de 5-10\% após sua ressecção cirúrgica. ${ }^{4,5}$

O diagnóstico na maioria das vezes é acidental, feito através da endoscopia. A aparência endoscópica do TCG assemelha-se a um pólipo séssil (menos frequentemente como pólipo pediculado), localizado em qualquer parte entre o reto e o ceco, preferencialmente na área anorretal e cólon direito ${ }^{5,8}$. As descrições de TCG gastrointestinal na literatura mundial têm apontado com raridade a apresentação em canal anal (Tabela 1).

Tabela 1 - Registro de Tumor de Células Granulares na literatura mundial.

\begin{tabular}{lllc}
\hline Autor & Ano & Localização & N. Casos \\
\hline Dae-Kyung Sohn & 2004 & Cólon & 01 \\
Al Bouzide A & 2003 & Margem anal & 01 \\
Cohen MG & 2000 & Canal anal & 01 \\
Atsushi Nakachi & 2000 & Reto & 01 \\
Giovanni Battista Rossi & 2000 & Cólon & 01 \\
Gursoy B & 1997 & Língua & 01 \\
Rivas Lacarte MP & 1996 & Língua & 01 \\
Melo CR & 1993 & Ceco e cólon & 01 \\
Mzabi Regaya S & 1992 & Trato digestivo & 01 \\
Kawaura A & 1987 & Cólon ascendente & 01 \\
Pruglo Iu V & 1985 & Reto & 01 \\
\hline
\end{tabular}


Para estadiar e avaliar a profundidade da invasão do tumor na parede anorretal pode ser realizada uma ultrassonografia endoanal. Porém, este método não diferencia um tumor submucoso benigno de um maligno.

O diagnóstico final é selado com os marcadores histológicos do TCG, que são: plump histiocyte-like, células neoplásicas bland-loking com citoplasma granular eosinófílico contendo acidófilos, PAS positivo, grânulos resistentes à diástase; pequeno núcleo uniforme, em que são ausentes as figuras mitóticas. Marcadores neurais, incluindo proteína S-100 ou NSE uniformemente expresso, também podem ser úteis. ${ }^{3}$

Até o momento, o conhecimento sobre seu potencial maligno ${ }^{1}$ ainda é reduzido. Porém, de acordo com os relatos na literatura, o seu curso é designado pelo tamanho, já que mais de $60 \%$ das metástases se correlacionam com TCG com diâmetro maior que $4 \mathrm{~cm}^{7}$

No passado, o tratamento proposto era a realização de uma colectomia total, uma cirurgia de grande porte que afeta a qualidade de vida do paciente. Novas definições surgem com análises das casuísticas mais recentes, como: a) a malignidade é de rara ocorrência, sendo fortemente relacionada com o seu tama- nho, e b) seu curso é predominantemente benigno, sendo poucos os relatos de malignidade até o momento. Desta forma, não se sustenta uma abordagem agressiva para o tratamento do paciente com TCG gastrointestinal. $9,10,11$

\section{CONCLUSÕES}

Concluímos que, nos casos em que sejam encontradas lesões nodulares de TCG menores que $2 \mathrm{~cm}$, o melhor tratamento é a ressecção endoscópica ou transanal, com um seguimento a curtos intervalos, além de realização de colonoscopia, anualmente. A endoscopia alta, visto que há maior probabilidade de surgimento de TCG no esôfago, deve ser lembrada sempre.

A maioria dos autores sugere colectomia total em casos de múltiplos tumores ao longo dos cólons. Nos casos de localização pontual, a colectomia é mencionada como boa proposta quando se encontra lesão maior que $4 \mathrm{~cm}$, devido ao seu alto risco de malignização.

De acordo com a revisão da literatura, o presente caso trata de uma forma rara de apresentação do TCG.

ABSTRACT: The authors report a case of a 28-years-old female patient in which were diagnosed multiples granular cell tumors in anal canal with no relationship to the complain. Granular cell tumor is incomum, usually a benign lesion that can appear anywhere in the body. It has a rare presentation in the gastrointestinal tract. On the literature we were able to find out only two cases in the anal canal. The discussion is about the diagnostic aspect of granular cell tumor in gastrointestinal tract, mainly in rectum and anal canal, diagnostic methods and the recommended therapy. It's either shown a review based on the world literature, emphasizing the granular cell tumor on anal canal.

Key words: Granular cell tumor; Granular cell Myoblastoma; Gastrointestinal tract; Rectum; Anal canal.

\section{REFERÊNCIAS}

1. Atsushi Nakachi, et al. Granular cell tumor of the rectum: a case report and review of the literature. J Gastroenterol 2000; 35:631-634.

2. Rossi, G, et al. Granular cell tumor of the colon: report of a case and review of the literature. J Clin Gastroenterol 2000; 30(2): 197-9.

3. Dae Kujung Sohn, et al. Granular cell tumor of the colon: report of a case and review of the literature. World J Gastroenterol 2004;10(16):2452-2454.

4. Lack, EE, et al. Granular cell tumor: a clinicopathologic study of 110 patients. J Surg Oncol 1980; 13:301-16.
5. Armin, A, et al. An immunoperoxidase investigation of S-100 protein in granular cell tumor myoblastomas: evidence for Schwann cell derivation. Am J Pathol 1983; 79:37-44.

6. Jardines, L, et al. Malignant granular cell tumor: report of a case and review of the literature. Surgery 1994; 116:4954.

7. Yamada, T, et al. Granular cell tumor of the ascending colon. Inter Med 1995; 34(7):657-60.

8. Kubaylat, MN, et al. Granular cell tumor of the colon [letter]. Dis Colon Rectum 1996;39(6):711.

9. Yasuda, I, et al. Endoscopic removal of granular cell tumor. Gastrointest Endosc 1995;41(2):163-7. 
10. Kawamoto, K, et al. Endoscopic submucosal tumorectomy for gastrointestinal submucosal tumor restricted to the submucosa: a new form of endoscopic minimal surgery. Gastrointest Endosc 1997;45(3):322-4.

11. Kajiyama, T, et al. Endoscopic resection of gastrointestinal submucosal lesions: a comparison between strip biopsy and aspiration lumpectomy. Gastrointest Endosc 1996; 44(4):404-10.
Endereço para correspondência: BIANCA ANDREUCCI LIMA MOREIRA SANTONI

Avenida Epitácio Pessoa, 4.180 - bl. 01 - apt. 501

22.471-001 - Rio de Janeiro (RJ)

Fax: (21) 2266-0777

E-mail : bianca.santoni@uol.com.br 